\title{
Elemene treatment for NSCLC with multiple CNS metastases: a case report and literature review
}

This article was published in the following Dove Press journal:

OncoTargets and Therapy

\author{
Yushan $\mathrm{Han}^{1, *}$ \\ Xia Zhang ${ }^{2, *}$ \\ Yishan Lu Lu $^{3,4}$ \\ Yan Dong' \\ Hong Fu' \\ Bin Zhang' \\ Yajie Gao' \\ 'Department of Oncology, The First \\ Affiliated Hospital of Dalian Medical \\ University, Dalian, People's Republic \\ of China; ${ }^{2}$ Department of Oncology, \\ The Fifth People's Hospital of Dalian, \\ Dalian, People's Republic of China; \\ ${ }^{3}$ Queen Mary University of London, \\ London, UK; ${ }^{4}$ Nanchang University, \\ Nanchang, People's Republic of China \\ *These authors contributed equally \\ to this work
}

\begin{abstract}
CNS metastases are common in patients with non-small-cell lung cancer (NSCLC) and is associated with poor prognosis. In NSCLC patients with EGFR mutations, and ALK fusion oncogene, chemotherapy is ineffective; however, targeted and pulse therapies may be used as alternative treatment options. Elemene can cross the blood-brain barrier and enter the brain tissue. In this paper, treatment consisting of elemene injections in a case of NSCLC with brain metastases, spinal metastases and a possible complication of leptomeningeal metastases is reported, and the efficacy of elemene in treating NSCLC with CNS metastases was investigated.
\end{abstract}

Keywords: NSCLC, CNS metastases, elemene

\section{Introduction}

The incidence of brain metastases in non-small-cell lung cancer (NSCLC) is as high as $50 \%,{ }^{1,2}$ whereas the incidence of spinal cord metastases is $0.4 \%,{ }^{3}$ and the incidence of leptomeningeal metastases (LM) is $2 \% .{ }^{4}$ Once central nervous system (CNS) metastases occurs, the prognosis of a patient is very poor. According to 1 study, with no treatment, the median survival of NSCLC patients with brain metastases was only 1-3 months ${ }^{4}$, and only 4-6 weeks in cases with LM. ${ }^{3}$ In NSCLC patients with EGFR mutations and ALK fusion oncogene, chemotherapy is ineffective; however, targeted and pulse therapies may be used as alternative treatment options. ${ }^{5-8}$ Elemene is a type of oil, with high volatility, that can cross the blood-brain barrier and enter the brain tissue. Previous studies suggested that elemene was effective in the treatment of brain metastases and that it could prolong the survival of patients. ${ }^{9,10}$ However, the treatment efficacy of elemene in cases of spinal metastasis with LM has rarely been reported. In this paper, treatment consisting of elemene injections in a case of NSCLC with brain metastases, spinal metastases and a possible complication of LM is reported, and the application value of elemene in the treatment of NSCLC with CNS metastases was investigated. Written informed consent was provided by the patient to have their case details, and any accompanying images, published. The patient's family was informed of this report and they provided their consent. This report was also approved by the First Affiliated Hospital of Dalian Medical University.

\section{Case report}

A 45-year-old female patient (surface area:1.72) sought treatment on November 5, 2012 due to gradually aggravated dizziness and headaches for 1 week. A brain MRI revealed multiple cerebral metastases, of which the large lesions measured $\sim 2.1 \times 1.9 \mathrm{~cm}$. A lung CT revealed space-occupying lesions in the tip of the right upper pulmonary lobe and hilum, multiple metastases in both lungs, and enlarged mediastinal lymph nodes. The bronchoscopic examination with bronchial brush and lavage liquid base inspection
Correspondence: Bin Zhang; Yajie Gao Department of Oncology, The First Affiliated Hospital of Dalian Medical University, Dalian, No 222 Zhongshan Road, Liaoning II6000, People's Republic of China

Tel/fax +864 II83635963

Email zhangbin_dlmu@I63.com; gaoyajie100@126.com
OncoTargets and Therapy 2018:1 / 6377-6382

Dovepress ff in 0

http://dx.do.org/10.2147/0TTS160970 (c) (1) (-) 2018 Han et al. This work is published and licensed by Dove Medical Press Limited. The full terms of this license are available at https://www.dovepress.com/terms.php C. hereby accept the Terms. Non-commercial uses of the work are permitted without any further permission from Dove Medical Press Limited, provided the work is properly attributed. For permission for commercial use of this work, please see paragraphs 4.2 and 5 of our Terms (https://www.dovepress.com/terms.php). 
showed poorly differentiated cancer cells that resembled adenocarcinoma. The pathology results revealed NSCLC, and a diagnosis of adenocarcinoma was considered. The diagnosis was stage IV cancer of the right lung, with metastases observed in both lungs, in the mediastinal lymph nodes and in the brain. One course of whole-brain radiotherapy was performed, dose tissue (DT) $40 \mathrm{~Gy}$, with a local dosage as high as 56 Gy. At the same time, oral chemotherapy consisting of temozolomide was given, and the primary symptoms were relieved after the radiotherapy. After that, 3D conformal radiotherapy for the mediastinal tumor was performed at a DT of 56 Gy. Simultaneously, gefitinib targeted drug therapy was provided, even though the EGFR mutation status was unknown. In February 2013, the follow-up lung CT scan showed the progression of pulmonary metastases. Subsequently, gefitinib treatment was discontinued, and 2 courses of chemotherapy (docetaxel: $75 \mathrm{mg} / \mathrm{m}^{2}+$ cisplatin: $75 \mathrm{mg} / \mathrm{m}^{2}$ ) were administered, with the efficacy evaluated as progressive disease. The chemotherapy was then changed to 2 cycles of the gemcitabine regimen (gemcitabine: $1 \mathrm{~g} / \mathrm{m}^{2}+$ cisplatin: $75 \mathrm{mg} / \mathrm{m}^{2}$ ), and the efficacy, with respect to the lung lesions, was evaluated as stable disease. However, the patient developed a headache during the third course of chemotherapy with the gemcitabine regimen. A brain MRI (Figure 1A and $\mathrm{B}$ ) revealed a cerebellar tentorial lesion and progression of the brain metastases. Temozolomide treatment was administered again for 3 months, but the patient's headache was not relieved. Glycopeptide fructose and dexamethasone $(10 \mathrm{mg} / \mathrm{d})$ were given to reduce the intracranial pressure, and the headache was slightly relieved. On September 13, 2013, 4 courses of pemetrexed combined with erlotinib were given, and the last dose of chemotherapy treatment
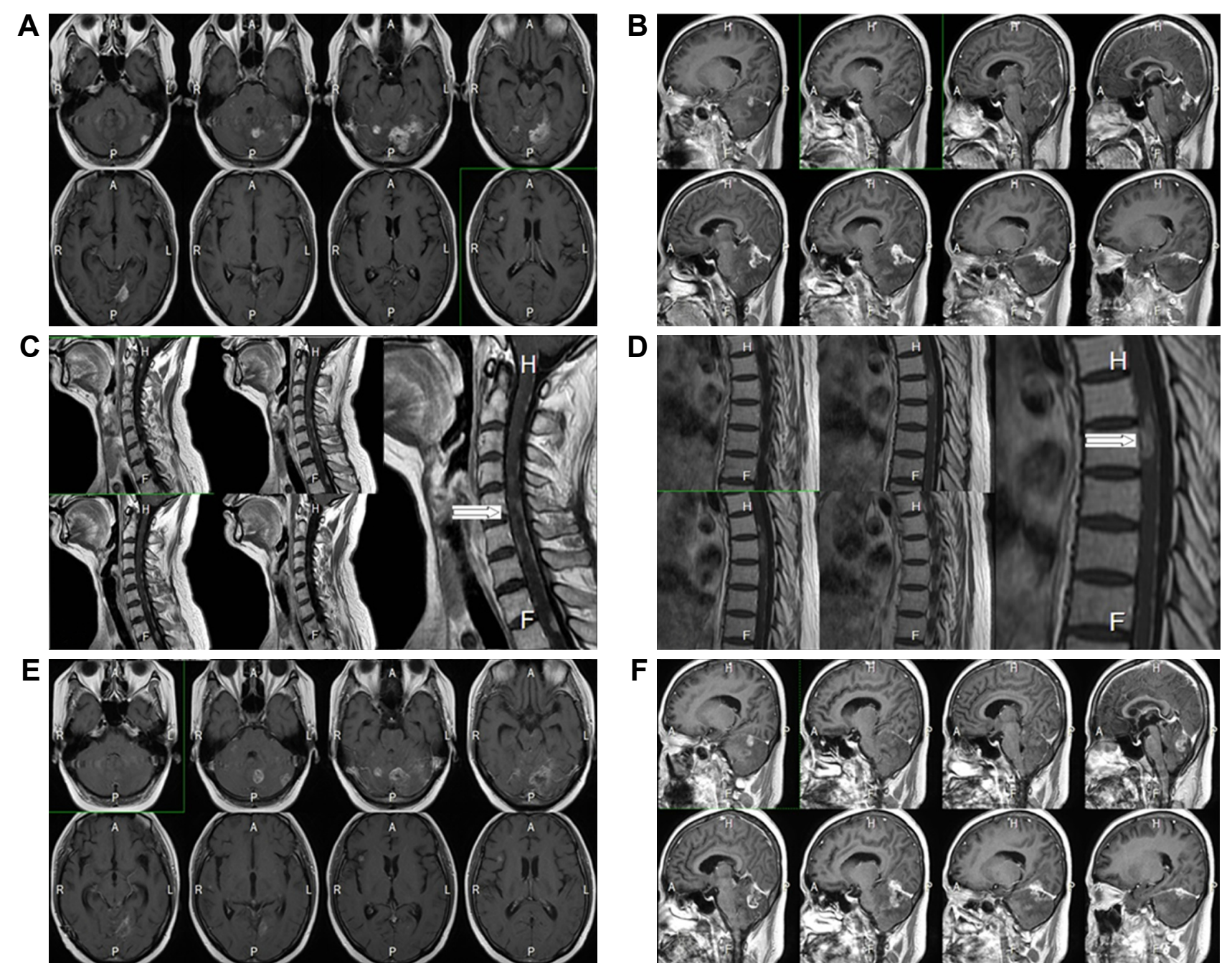

Figure I Brain MRI showing brain metastasis.

Notes: Cerebellar tentorial lesion (A) horizontal position; (B) sagittal position. The signal of cervical and thoracic medulla is uneven spinal metastases-white arrows indicate metastatic lesions of the spinal cord (C, D); cerebellum and occipital lobe metastasis (E, F).

Abbreviations: $A$, anterior; $F$, foot side; $H$, head side; L, left; $P$, posterior; $R$, right. 
was administered on December 12, 2013. The headache was slightly relieved during the treatment. On January 14, 2014, the headache worsened and was accompanied by projectile vomiting, numbness, and pain in the right limb and shoulder. An emergency head CT scan revealed multiple metastases in the bilateral cerebellar hemispheres, cerebellar vermis, right frontal lobe, temporal lobe and the brain midline, which were aggravated in comparison to the lesions seen on December 2013. The enhanced head and spinal MRI (Figure $1 \mathrm{C}-\mathrm{F})$ revealed uneven signals in the cervical and thoracic spinal cord, as well as patchy high signals and nodular shadow in the posterior cerebellum and occipital lobe. When reviewing the patient's medical history cerebellar and occipital tumor metastases as well as cervical and thymic metastases were also considered. The diagnosis of spinal metastasis was clear; the patient had a performance status 3 and was, therefore, not suitable for chemotherapy. EGFR and ALK genes were detected and no mutation was found. From January 25 to January 30,2014 , elemene $(120 \mathrm{~mL}$, intravenously guttae [IVGTT], quaque die [QD]) and dexamethasone $(10 \mathrm{mg} / \mathrm{d})$ were administered, which relieved the dizziness and headache. On January 30, the patient was discharged, and oral elemene was administered at home. On February 7, 2014, the numbness in both legs had gradually become worse. From February 7, 2014, to February 20, 2014, elemene (120 mL, IVGTT, QD) was continuously administered, which gradually alleviated both the headache, and numbness in both legs. From February 20, 2014, to March 15, 2014, the medication was withdrawn, and the patient experienced intermittent simple epileptic seizures and frequent headache episodes. From March 15, 2014, to March 21, 2014, elemene (120 mL, IVGTT, QD) was continued, and the patient's headache was relieved. However, the patient experienced type 1 respiratory failure, and her general condition was poor. Nutritional support and symptomatic treatment were provided. The patient died on April 17, 2014, and the cause of death was lung cancer with brain metastases, respiratory function failure and possible brain hernia.

\section{Discussion}

CNS metastases, including brain metastases, LM, spinal metastases and spinal membrane metastasis affects patient survival and quality of life. In 1 study, even after treatment, the median survival time of lung cancer patients with brain metastases was only 3-6 months, ${ }^{11}$ and the prognosis was even worse if the patient also had spinal cord metastases and LM. The blood-brain barrier is the major factor that affects treatment efficacy. The blood-brain barrier prevents entry of harmful substances into the brain from the blood, but it also inhibits the entry of chemotherapy drugs into the brain, which affects the efficacy of chemotherapy in cancer patients with brain metastases. Patients who are diagnosed with brain and spinal cord metastases most likely also have LM. The diagnosis of LM is difficult, and LM often cannot be revealed by conventional imaging. Enhanced MRI scans have a falsenegative rate of $65 \%$ and a false-positive rate of $10 \%$ in the diagnosis of $\mathrm{LM},{ }^{12}$ while a plain $\mathrm{CT}$ scan has a limited value in the diagnosis of LM. ${ }^{13}$ For the patient in this case study, the diagnosis of spinal metastasis was clear. The MRI of this patient revealed uneven cervical spinal cord signal, multiple spots of high signal shadow in the enhanced posterior spinal cord and patchy high signal shadow and nodule shadow in the posterior cerebellum and occipital lobe. The MRI also showed uneven thoracic spinal cord signal, multiple spots of high signal shadow in the enhanced thoracic spinal cord, as well as patchy and round-like abnormal signal shadow in the bilateral cerebellar hemispheres, cerebellar vermis, right forehead, temporal lobe and brain midline. According to the imaging findings, the spinal cord metastasis may have been caused by dissemination and seeding via the cerebrospinal fluid. ${ }^{14-16}$ This combined with arterial hematogenous metastases and intracranial metastasis leads to invasion of the spinal pia mater and the spread to the spinal cord parenchyma. Considering the patient's symptoms including epileptic seizures, numbness in both legs, numbness in the right limbs, shoulders and back, as well as pain, headache and nausea with projectile vomiting, the patient was strongly believed to have LM. In 1 study, the prognosis of patients with LM was very poor, the chemotherapy and targeted treatment were ineffective, and the median survival of the untreated patients was only 4-6 weeks. ${ }^{3}$

Tyrosine kinase inhibitors (TKIs) play an important role in the treatment of brain metastases and LM. Togashi et al found that 8 days after the administration of erlotinib in NSCLC patients with CNS metastasis, the cerebrospinal fluid permeability rates of erlotinib and its major active metabolites were $5.1 \%$ and $5.8 \%$, respectively, which confirms that EGFR-TKIs can indeed cross the blood-brain barrier and exert an anti-tumor effect. ${ }^{17}$ Lee et $\mathrm{al}^{18}$ explored the impact of targeted therapies for the treatment of NSCLC-LM. All patients underwent chemotherapy by intrathecal injection, and 4 cases received whole brain radiation therapy. Among them, 14 patients received erlotinib (150 mg/day), and 11 patients received gefitinib (250 mg/day). The negative rate of CSF cytology in the erlotinib group was relatively high $(64.3 \%$ vs $9.1 \%, P=0.012)$. The overall survival was 
9.5 months and 4.4 months for the erlotinib group and the gefitinib group, respectively. ${ }^{18}$ Umemura et al ${ }^{19}$ analyzed 51 patients with a cytological diagnosis of NSCLC-LM, and of these, the EGFR mutation status was determined in 30 patients. The results showed no EGFR gene mutation in 7 cases, mutations in exon 21 in 10 cases and mutations in exon 19 in 13 cases. After treatment with erlotinib (150 mg/day) or gefitinib (250 mg/day), the median survival time was $1.4,7.1$ and 11.0 months, respectively, and the median progression-free survival was $0.9,2.0$ and 7.8 months, respectively. Grommes et al treated 9 patients with LM and brain metastases using intermittent highdose pulsed erlotinib (1,000-1,500 mg/week), and the average median progression-free survival was 2.7 months (0.8-14.5 months), while the clinical symptoms, CSF and imaging findings were significantly improved. ${ }^{5-7}$ Kuribayashi et $\mathrm{al}^{20}$ reported a case of ALK-positive lung adenocarcinoma. In patients that presented with LM and spinal cord metastases and were resistance to treatment using the first generation of crizotinib, treatment with second generation ALK TKI alectinib proved to be effective. Moreover, the MRI showed that the numbers of LM and spinal cord metastatic lesions were significantly reduced. Wang et $\mathrm{al}^{21}$ reported that a small molecule TKI was used in 4 NSCLC patients with spinal cord metastases and that these patients had an Med O Sur of 5.8 months (95\% CI, range 1.9-9.6 months). According to the literature, for spinal cord metastases, in addition to targeted therapies, surgical treatment and radiotherapy may be used to alleviate the symptoms of the patients. ${ }^{22-24}$ Chemotherapy drugs that can cross the blood-brain barrier and play a certain anti-tumor role include temozolomide, vinorelbine and pemetrexed. ${ }^{25-27}$ However, both chemotherapy and surgical treatment have a high requirement in terms of the Karnofsky Performance Score. The patient in this study had end-stage disease with long-term bed rest and poor physical condition, and the symptoms of CNS metastases were obvious: Karnofsky Performance Score of 40 and no indications for chemoradiotherapy or surgery. In the early period, progression occurred during treatment with an EGFR-TKI targeting drug. Due to the lack of an EGFR mutation, only treatment with traditional Chinese medicine in addition to the best supportive treatment could be considered, but it is difficult to select the most appropriate traditional Chinese medicine.

Capillary endothelial cells are a key part of the bloodbrain barrier, as they have a good lipophilicity that can facilitate the passage of small molecule TKIs and lipophilic substances. ${ }^{28}$ Elemene is a type of volatile oil that has a strong lipid solubility. After intravenous administration, a portion of elemene can cross the blood-brain barrier and enter the brain tissue. Fundamental research ${ }^{29-33}$ has confirmed that elemene injection exerts a killing effect on the brain metastases of lung cancer and liver cancer as well as those of glioblastoma. Elemene can induce the apoptosis and differentiation of these tumor cells. Elemene was applied to lung cancer cell lines Anip-937, SPC-Al and A549, and the results showed that it had strong growth inhibition, and killing effect, on all 3 lung cancer cells. ${ }^{29-34}$ This effect was quantifiable and the IC50 levels measured in the cell lines at 48 hours, were $38.2 \mu \mathrm{g} / \mathrm{mL}$, $29.3 \mu \mathrm{g} / \mathrm{mL}$, and $32.4 \mu \mathrm{g} / \mathrm{mL}$, respectively. Jusheng et $\mathrm{al}^{31}$ applied carotid artery infusion, and intravenous and topical treatment in 30 cases of primary and metastatic brain tumors for the first time in 1990. An effective rate as high as $63.3 \%$ and minor toxic reactions were observed. Jiang et $\mathrm{al}^{35}$ indicated that elemene could enhance the sensitivity of lung cancer with brain metastases to radiotherapy via the induction of apoptosis, the upregulation of p53 expression and the downregulation of bcl-2 expression. Ailing et $\mathrm{al}^{36}$ conducted a meta-analysis of 1,075 lung cancer patients with brain metastases and found that, compared with radiotherapy alone, elemene treatment combined with radiotherapy could significantly inhibit tumor growth, reduce the side effects of radiotherapy and improve patient quality of life. However, experience guiding the treatment of spinal cord and meningeal metastases is lacking.

At the end stage of the patient's life, after family members agreed to try traditional Chinese medicine, the symptoms of this patient were noticeably relieved with elemene. The frequency and degree of nausea, vomiting and headache were also relieved. Sleep and eating habits improved, the patient's mental state was healthier, and quality of life was improved. However, the patient's symptoms worsened again during the period when the medication was withdrawn by the patient, which indicates that elemene played a positive role in the treatment of the disease. The patient had a total treatment duration of 1 year and 5 months, and the survival time after the application of elemene was 83 days; therefore, elemene achieved its purpose as a soothing medicine. However, the patient ultimately did not survive and died of respiratory failure due to brain metastases. Whether elemene can play a positive role in the treatment of CNS metastases still requires further investigation and an analysis of more cases. The purpose of the present study was to report this case, and to garner the attention of clinicians.

\section{Acknowledgment}

This work was supported by the Liaoning Provincial Natural Science Foundation (project no. LQ2017024). 


\section{Disclosure}

The authors report no conflicts of interest in this work.

\section{References}

1. Khuntia D, Brown P, Li J, Mehta MP. Whole-brain radiotherapy in the management of brain metastasis. J Clin Oncol. 2006;24(8): 1295-1304.

2. Hubbs JL, Boyd JA, Hollis D, Chino JP, Saynak M, Kelsey CR. Factors Associated With the Development of Brain Metastases. Cancer. 2010; 116(21):5038-5046.

3. Lee SS, Kim MK, Sym SJ, et al. Intramedullary spinal cord metastases: a single-institution experience. $J$ Neurooncol. 2007;84(1):85-89.

4. Sudo J, Honmura Y. Meningeal carcinomatosis in patients with lung cancer. Nihon Kokyūki Gakkai Zasshi. 2006;44(11):795-799.

5. Clarke JL, Pao W, Wu N, Miller VA, Lassman AB. High dose weekly erlotinib achieves therapeutic concentrations in CSF and is effective in leptomeningeal metastases from epidermal growth factor receptor mutant lung cancer. J Neurooncol. 2010;99(2):283-286.

6. Grommes C, Oxnard GR, Kris MG, et al. "Pulsatile" high-dose weekly erlotinib for CNS metastases from EGFR mutant non-small cell lung cancer. Neuro Oncol. 2011;13(12):1364-1369.

7. Cessot A, Blanchet B, Goldwasser F. Erlotinib treatment of meningeal carcinomatosis in lung cancer: more is better. Ann Oncol. 2014; 25(10):2093-2094.

8. Jackman DM, Cioffredi LA, Jacobs L, et al. A phase I trial of high dose gefitinib for patients with leptomeningeal metastases from non-small cell lung cancer. Oncotarget. 2015;6(6):4527-4536.

9. Li QQ, Lee RX, Liang H, Zhong Y, Qq L. Anticancer activity of $\beta$-Elemene and its synthetic analogs in human malignant brain tumor cells. Anticancer Res. 2013;33(1):65-76.

10. Chen X, Wang Y, Luo H, et al. $\beta$-elemene acts as an antitumor factor and downregulates the expression of survivin, Bcl-xL and Mta-1. Mol Med Rep. 2012;6(5):989-995.

11. D'Antonio C, Passaro A, Gori B, et al. Bone and brain metastasis in lung cancer: recent advances in therapeutic strategies. Ther Adv Med Oncol. 2014;6(3):101-114.

12. Clarke JL, Perez HR, Jacks LM, Panageas KS, Deangelis LM. Leptomeningeal metastases in the MRI era. Neurology. 2010;74(18): $1449-1454$.

13. Ximao L, Wansheng $\mathrm{L}, \mathrm{Hu}$ Maoqing, et al. MRI findings of metastatic meningeal carcinomatosis. Zhongguo CT He MRI Za Zhi 2009;7(3):15-18.

14. Connolly ES, Winfree CJ, Mccormick PC, Cruz M, Stein BM. Intramedullary spinal cord metastasis: report of three cases and review of the literature. Surg Neurol. 1996;46(4):329-337.

15. Findlay JM, Bernstein M, Vanderlinden RG, Resch L. Microsurgical resection of solitary intramedullary spinal cord metastases. Neurosurgery. 1987;21(6):911-915.

16. Okamoto H, Shinkai T, Matsuno Y, Saijo N, Hiroaki Okamoto T. Intradural parenchymal involvement in the spinal subarachnoid space associated with primary lung cancer. Cancer. 1993;72(9):2583-2588.

17. Togashi Y, Masago K, Fukudo M, et al. Cerebrospinal fluid concentration of erlotinib and its active metabolite OSI-420 in patients with central nervous system metastases of non-small cell lung cancer. J Thorac Oncol. 2010;5(7):950-955.

18. Lee E, Keam B, Kim DW, et al. Erlotinib versus gefitinib for control of leptomeningeal carcinomatosis in non-small-cell lung cancer. $J$ Thorac Oncol. 2013;8(8):1069-1074.

19. Umemura S, Tsubouchi K, Yoshioka H, et al. Clinical outcome in patients with leptomeningeal metastasis from non-small cell lung cancer: Okayama Lung Cancer Study Group. Lung Cancer. 2012; 77(1):134-139.
20. Xu Y, Zhong W, Zhao J, et al. Clinical Features of Intradural Extramedullary Spinal Cord Metastases in Primary Lung Cancer. Zhongguo Fei Ai Za Zhi. 2016;19(8):539-544.

21. Kuribayashi H, Abe S, Kuse N, et al. Marked improvement in leptomeningeal carcinomatosis and spinal cord metastases following alectinib treatment of crizotinib-resistant, ALK-positive lung adenocarcinoma. I Can Conf J. 2016;5(2):69-72.

22. Lei M, Liu Y, Liu S, Wang L, Zhou S, Zhou J. Individual strategy for lung cancer patients with metastatic spinal cord compression. Eur $J$ Surg Oncol. 2016;42(5):728-734.

23. Nicole White MD. Metastatic Spinal Cord Compression: Presentation, Diagnosis, and Management. Hospital Medicine Clinics. 2016; 5(3):452-465.

24. Giraldo A, Benavente S, Ramos M, et al. Effectiveness of radiotherapy for metastatic spinal cord compression in patients with short life expectancy. Rep Pract Oncol Radiother. 2017;22(1):58-63.

25. Bailon O, Chouahnia K, Augier A, et al. Upfront association of carboplatin plus pemetrexed in patients with brain metastases of lung adenocarcinoma. Neuro Oncol. 2012;14(4):491-495.

26. Bearz A, Garassino I, Tiseo M, et al. Activity of Pemetrexed on brain metastases from Non-Small Cell Lung Cancer. Lung Cancer. 2010; 68(2):264-268.

27. Giorgio CG, Giuffrida D, Pappalardo A, et al. Oral temozolomide in heavily pre-treated brain metastases from non-small cell lung cancer: phase II study. Lung Cancer. 2005;50(2):247-254.

28. Domínguez A, Álvarez A, Suárez-Merino B, Goñi-de-Cerio F. Neurological disorders and the blood-brain barrier. Strategies and limitations for drug delivery to the brain. Rev Neurol. 2014;58(5):213-224.

29. Li LJ, Zhong LF, Jiang LP, Geng CY, Zou LJ. $\beta$-Elemene radiosensitizes lung cancer A549 cells by enhancing DNA damage and inhibiting DNA repair. Phytother Res. 2011;25(7):1095-1097.

30. Chen W, Lu Y, Wu J, Gao M, Wang A, Xu B. Beta-elemene inhibits melanoma growth and metastasis via suppressing vascular endothelial growth factor-mediated angiogenesis. Cancer Chemother Pharmacol. 2011;67(4):799-808.

31. Li QQ, Wang G, Zhang M, Cuff CF, Huang L, Reed E. beta-Elemene, a novel plant-derived antineoplastic agent, increases cisplatin chemosensitivity of lung tumor cells by triggering apoptosis. Oncol Rep. 2009; 22(1):161-170.

32. Zhu Y, Hu J, Shen F, Shen H, Liu W, Zhang J. The cytotoxic effect of $\beta$-elemene against malignant glioma is enhanced by baseexcision repair inhibitor methoxyamine. $J$ Neurooncol. 2013;113(3): 375-384.

33. Wang G, Li X, Huang F, et al. Antitumor effect of beta-elemene in non-small-cell lung cancer cells is mediated via induction of cell cycle arrest and apoptotic cell death. Cell Mol Life Sci. 2005;62(7-8): 881-893.

34. Jusheng H, Yinghui X. Clinical study on the treatment of intracranial malignancy by $\beta$-elemene. Chinese Journal of Neurosurgery. 1994;4: $225-228$.

35. Jiang H, Ma S, Feng J. In vitro study of radiosensitization by $\beta$-Elemene in A549 cell line from adenocarcinoma of lung. The Chin-German $J$ Clin Oncol. 2009;8(1):12-15.

36. Ailing CAO, Hailang HE. Meta-analysis of Elemene Injection Combined with Radiotherapy in Treating Brain Metastasis of Lung Cancer. Tradi Chin Drug $R \&$ C Pharmacol. 2016;27(6):880-886. 


\section{Publish your work in this journal}

OncoTargets and Therapy is an international, peer-reviewed, open access journal focusing on the pathological basis of all cancers, potential targets for therapy and treatment protocols employed to improve the management of cancer patients. The journal also focuses on the impact of management programs and new therapeutic agents and protocols on

patient perspectives such as quality of life, adherence and satisfaction. The manuscript management system is completely online and includes a very quick and fair peer-review system, which is all easy to use. Visit http://www.dovepress.com/testimonials.php to read real quotes from published authors.

Submit your manuscript here: http://www.dovepress.com/oncotargets-and-therapy-journal 